\title{
COMPARATIVE CLIMICAL STUDIES ON THE EFFECT OF THIAMINE AND COCARBOXYLASE
}

\author{
TOICHIRO SAWADA, KAZUMA MIYAJI, IKUO SHIGEMATSU, HIDEHIKO NAGAO, \\ MUNEAKI ABE AND KEIICHIRO TSUKAMOTO
}

\author{
Department of Internal Medicine, School of Medicine, \\ Kyushu University, Fukuoka
}

(Received February 2, 1957)

\begin{abstract}
That cocarboxylase ( $\mathrm{CoC})$ is the active form of thiamine in the body is an accepted idea. Since Ochoa (1) showed that the phosphorylation of thiamine takes place most actively in the liver, conditions or diseases of the liver which disturb the mechanism of phosphorylation have become important problems. The report of Markees et al. (6) that the injections of $100-200 \mathrm{mg}$ $\mathrm{CoC}$ at intervals of several hours are effective in diabetic coma is especially worthy of note. Diabetes is thus assumed to be a disease, in which thiamine phosphorylation is disturbed. Leuthardt (2) later succeeded in isolating a thiamine-phosphorylating enzyme, thiaminokinase, from the liver of the rat. This has much contributed to examining conditions whirh disturb thiamine phosphorylation and to advancing methods for restoring the disturbance.

We had previously studied the effect of thiamine and $\mathrm{CoC}$ using the Sawada test as an index and had found that the effect of $\mathrm{CoC}$ was superior to that of thiamine in accelerating liver function, but the investigation was not in detail. Sewaki (3) later reported similar results using the same method. In the present study, the rise in blood thiamine level, excretion of thiamine in urine and the effect on liver function were studied. The effect of insulin on the production of the esterified thiamine in blood was also examined.
\end{abstract}

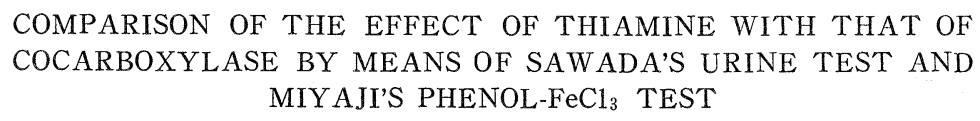

\section{Sawada's Urine Test}

Three-Hour Method of the Urine Test-Measurements were made early in the morning with an empty stomach. Initial urine without loading (onehour urine after complete urination), intermediate urine (one-hour urine after an intravenous injection of $20 \mathrm{ml}$ of 20 per cent fructose in 1 minute) and final urine (the second one-hour urine after loading) were collected. The keto acid of each was colored by the ordinary method (4). The amount of the solution in each test tube was $4 \mathrm{ml}$ ( $1 \mathrm{ml}$ urine, $1 \mathrm{ml}$ 2,4-dinitropheny1hydrazine solution, $2 \mathrm{ml} \mathrm{NaOH})^{1}$. When the coloration of the intermediate

\footnotetext{
${ }^{1}$ Thirty minutes after adding the hydrazine solution to the urine at room temperature, the $\mathrm{NaOH}$ solution is added.
} 
and final urines was deeper than that of the initial, the latter was added to the former until the color of each became the same. If, for example, the amount of the fluid in each test tube was 4,8 and $6 \mathrm{ml}$, respectively, the concentration ratio of keto acid is $1: 2: 1.5$. Thus, the results of this study were designated as the ratio to the initial urine which was taken as 1 . The smaller the ratio, the greater was the effect.

Miyaji's phenol- $\mathrm{FeCl}_{3}$ reaction (5) was carried out by using the initial and intermediate urines (occasionally the final urine) for examining the liver function. In this test $\mathrm{FeCl}_{3}$ is added to a phenol solution until a purple color is obtained to which urine is added dropwise until the mixture is completely discolored. Aside from liver dysfunction there is little difference in the discoloring ability between the initial and intermediate urines. In liver dysfunction, however, the ability is greater, especially that of the intermediate urine. Assuming the amount of urine required for discoloration to be $a \mathrm{ml}$ for the initial urine and $b \mathrm{ml}$ for the intermediate urine $(c \mathrm{ml}$ if measurements are carried out with up to the final urine), $a / b$ becomes large in liver disturbances, often exceeding 1.7. Therefore, in this experiment $a / b$ values were determined as the indices of liver disturbance.

After having determined both the reactivities in urine test and the indices of liver disturbance of the test subject, $10 \mathrm{mg}$ thiamine was injected intravenously on the following day and the urine reactions were retested. Several days later $20 \mathrm{mg}$ thiamine was injected again and the measurements were repeated. After another several days, $27 \mathrm{mg} \mathrm{CoC}$, equivalent to $20 \mathrm{mg}$ thiamine, was injected and the determinations were carried out.

One-Hour Method of the Urine Test - The phenol- $\mathrm{FeCl}_{3}$ reaction was not examined in this case. Only the urine reaction was tested using the onehour method instead of three-hour method:

(a) Initial urine: 30-minute urine after complete urination was collected.

(b) Final urine: 30-minute urine after an intravenous injection of $5 \mathrm{ml}$ of 20 per cent fructose in 20-30 seconds. Further procedure is the same as the three-hour method. The effect of thiamine was thus compared with that of $\mathrm{CoC}$.

\section{Results}

The comparison of the effect of thiamine with that of $\mathrm{CoC}$ determined by

TABLE I

Comparative Effect of Thiamine and Cocarboxylase in the

Three-Hour Method of the Urine Test

\begin{tabular}{l|c|c}
\hline \multirow{2}{*}{ Vitamin administered } & \multicolumn{2}{|c|}{ Average of 20 cases } \\
\cline { 2 - 3 } & Urine test ratio & $\mathrm{FeCl}_{\mathbf{3}}$ test \\
\hline Control & 1.22 & 1.63 \\
Thiamine, $10 \mathrm{mg}$ & 1.28 & 1.63 \\
Thiamine, $20 \mathrm{mg}$ & 1.05 & 1.31 \\
CoC, $27 \mathrm{mg}$ & 1.12 & 1.13 \\
\hline
\end{tabular}


the three-hour method is shown in Table I. It can be seen from the Table I that the average urine test ratio of 20 cases in the normal control without loading is 1.22 , whereas it is 1.28 after loading with $10 \mathrm{mg}$ thiamine, 1.05 after loading with $20 \mathrm{mg}$ thiamine and 1.12 after loading with $27 \mathrm{mg} \mathrm{CoC}$. In other words, $10 \mathrm{mg}$ thiamine had little effect, but a marked effect was observed after loading with $20 \mathrm{mg}$ thiamine. There was little difference, however, between $20 \mathrm{mg}$ thiamine and $27 \mathrm{mg}$ CoC. Taking individual cases into consideration, an injection of $27 \mathrm{mg} \mathrm{CoC}$ was superior in effect in 7 out of 16 cases, and without change in 2 , so there was little difference compared with an injection of $20 \mathrm{mg}$ thiamine. Liver dysfunction indices for the control, the loading of $10 \mathrm{mg}$ thiamine, $20 \mathrm{mg}$ thiamine and $27 \mathrm{mg} \mathrm{CoC}$ were found to be $1.63,1.63,1.31$ and 1.13 , respectively. Namely, there was no change after loading with $10 \mathrm{mg}$ thiamine, but a marked benefical effect was observed after loading with $20 \mathrm{mg}$ thiamine and the effect was even more pronounced after loading with $27 \mathrm{mg} \mathrm{CoC}$, a marked difference being observable between thiamine and CoC. Taking individual cases into consideration, $\mathrm{CoC}$ was found superior to thiamine in effect in all the cases.

Examinations of the initial and intermediate urines according to the threehour method gave the results presented in Table II. The results after loading with $10 \mathrm{mg}$ thiamine were roughly the same as the above experiment, but

TABLE II

Comparative Effect of Thiamine and Cocarboxylase in the Three-Hour Method of the Urine Test Using Initial and Intermediate Urine

\begin{tabular}{l|c|c|} 
& \multicolumn{2}{|c|}{ Average of 12 cases } \\
\cline { 2 - 3 } Vitamin administered & Urine test ratio & $\mathrm{FeCl}_{3}$ test \\
Control & 2.47 & 1.63 \\
Thiamine, $10 \mathrm{mg}$ & 2.49 & 1.66 \\
Thiamine, $20 \mathrm{mg}$ & 2.17 & 1.31 \\
CoC, $27 \mathrm{mg}$ & 2.01 & 1.11
\end{tabular}

there were a greater number of cases in which a difference between $20 \mathrm{mg}$ thiamine and $27 \mathrm{mg} \mathrm{CoC}$ was apparent, $\mathrm{CoC}$ being more effective in all the cases. $\mathrm{CoC}$ was found to be superior to thiamine in 8 of the 11 cases sub-

TABLE III

Comparative Effect of Thiamine and Cocarboxylase

in the One-Hour Method of Urine Test

The figures show urine test ratios.

\begin{tabular}{l|c}
\hline & Average of 13 cases \\
\hline Control & 1.31 \\
Thiamine, $10 \mathrm{mg}$ & 1.21 \\
CoC, $14 \mathrm{mg}$ & 1.15 \\
\hline
\end{tabular}


jected to the urine test.

With one-hour method, as can be seen in Table III, the average of 13 cases was 1.31 in the control urine, whereas it became 1.21 after loading with $10 \mathrm{mg}$ thiamine and 1.15 after loading with $14 \mathrm{mg} \mathrm{CoC}$, a definite difference being detected between the loading with $10 \mathrm{mg}$ thiamine and that with $14 \mathrm{mg}$ CoC. Taking individual cases into consideration, $\mathrm{CoC}$ was found superior in effect to thiamine in 9 out of 13 cases.

\section{COMPARISON OF THIAMINE WITH COCARBOXYLASE IN THE RISE IN BLOOD THIAMINE LEVEL AND URINARY THIAMINE EXCRETION}

\section{Method}

A comparison of the effect between $9 \mathrm{mg}$ thiamine and an aqueous preparation of $5 \mathrm{mg} \mathrm{CoC}$ plus $5 \mathrm{mg}$ thiamine nitrate was carried out in the following manner. After stopping all forms of medication, $2 \mathrm{mg}$ thiamine was given orally for a period of 1 week. Blood was then withdrawn at $8: 45$ a. $\mathrm{m}$. and the thiamine content measured. Thereafter, the aqueous solution of $\mathrm{CoC}$ plus thiamine nitrate was given in a single subcutaneous injection once every day at 9:00 a.m. for 8 successive days. On the ninth day, blood was withdrawn before breakfast at $8: 45 \mathrm{a} . \mathrm{m}$. and the thiamine content measured. The value thus obtained was compared with the previous value. Oral administration of thiamine in a dose of $2 \mathrm{mg}$ a day was again continued for $7-8$ days until the blood thiamine level returned to the former value. Thiamine was then loaded in the same manner as before in a dose of $9 \mathrm{mg}$ a day and the rise in blood thiamine level was measured. The rise in blood thiamine level was thus compared between thiamine and $\mathrm{CoC}$ plus thiamine nitrate.

The urinary thiamine excretion was then compared between the loading with $10 \mathrm{mg} \mathrm{CoC}$ plus $10 \mathrm{mg}$ thiamine nitrate and that with $20 \mathrm{mg}$ thiamine. All forms of medication were prohibited for 5-7 days. $\mathrm{CoC}$ and thiamine nitrate were then given subcutaneously at 7:00 a.m. and the urine collected after 4 and 8 hours. The thiamine content of the two urine samples was then measured. The subject wes permitted to take breakfast and lunch as usual. After one week, the same experiment was carried out using $20 \mathrm{mg}$ thiamine in place of the $\mathrm{CoC}$ mixture. The values obtained in each experiment were compared.

Pure $\mathrm{CoC}$ and thiamine were then compared as in the previous experiment: $5 \mathrm{mg} \mathrm{CoC}$ or $4 \mathrm{mg}$ thiamine were given for 8 days and the rise in blood thiamine level was measured and compared. In order to study the rise in blood thiamine level in more detail, blood was collected on the 4 th, 7 th and 10 th day and 4 days after termination of administration while giving the injections every day in one case and the thiamine levels were determined. Other experimental condition was identical to that of the experiment using thiamine and CoC plus thiamine nitrate.

\section{Results}

The average rise in blood thiamine level after a single injection of $9 \mathrm{mg}$ 
thiamine or $5 \mathrm{mg} \mathrm{CoC}$ plus $5 \mathrm{mg}$ thiamine nitrate in 7 cases was found to be $2.3 \mathrm{r} / 100 \mathrm{ml}$ of total thiamine and $1.9 \mathrm{r} / 100 \mathrm{ml}$ of esterified thiamine in the case of $\mathrm{CoC}$ plus thiamine nitrate and 1.6 and $1.2 \gamma / 100 \mathrm{ml}$, respectively, in the case of thiamine; viz. there was little difference between the two.

When $10 \mathrm{mg}$ CoC plus $10 \mathrm{mg}$ thiamine nitrate or $20 \mathrm{mg}$ thiamine was injected subcutaneously, the urinary thiamine was $650 r$ at the first 4 hours and $279 \mathrm{r}$ more at the second 4 hours following the injection of $20 \mathrm{mg}$ thiamine. Considering, however, that $20 \mathrm{mg}$ thiamine is more in quantity by about $3000 \mathrm{r}$ than $10 \mathrm{mg}$ CoC plus $10 \mathrm{mg}$ thiamine nitrate, the difference between the two is scarcely recognized. Following successive injections of $5 \mathrm{mg}$ pure $\mathrm{CoC}$ or $4 \mathrm{mg}$ thiamine for 8 days, the rise in blood thiamine level in 2 cases differed scarcely between the two. After giving subcutaneously $10 \mathrm{mg}$ pure $\mathrm{CoC}$ or $7 \mathrm{mg}$ thiamine every day, the rise in the blood thiamine level on the $4 \mathrm{th}, 7 \mathrm{th}$ and 10 th days was followed and found on the 10 th day to be $13.0 \mathrm{r} / 100 \mathrm{ml}$ for the former, $8.0 \mathrm{r} / 100 \mathrm{ml}$ for the latter, a result showing the superiority of $\mathrm{CoC}$, inspite of only one case.

\section{TRANSFER OF THIAMINE AND COCARBOXYLASE INTO ERYTHROCYTES}

\section{Method}

Fifteen $\mathrm{ml}$ whole blood was divided into 3 equal portions. A physiological saline solution was added to each up to $40 \mathrm{ml}$. After gentle shaking for 10 minutes, the solutions were centrifuged first for 5 minutes at $500 \mathrm{rpm}$, then for 30 minutes at $1000 \mathrm{rpm}$, the supernatant being discarded. This procedure was repeated twice.

A physiological saline solution was then added to the washed erythrocytes up to $40 \mathrm{ml}$. To the first suspension was added $\mathrm{CoC}$ in a concentration of $31.25 \gamma / 100 \mathrm{ml}$, to the second was added thiamine in concentration of $25 \gamma / 100 \mathrm{ml}$ and the third served as a control. The solutions were shaken lightly for 1 hour while warming in the palm of the hand and centrifuged for 30 minutes at $1000 \mathrm{rpm}$, the supernatant being discarded. The erythrocytes were then washed twice with $40 \mathrm{ml}$ of a physiological saline solution as above. The thiamine content of each was then determined.

\section{Results}

The thiamine content in $\gamma$ per $100 \mathrm{ml}$ of the erythrocytes of the control was 16.0, that of the thiamine-supplemented sample was 15.8 and that of the CoC-supplemented sample was 16.8 , viz. scarcely any difference could be recognized among the three, showing that the transfer of thiamine or $\mathrm{CoC}$ into erythrocytes in vitro hardly takes place.

COMPARISON OF THE EFFECT OF THIAMINE, COCARBOXYLASE AND THIAMINE PROPYL DISULFIDE ON SANTONIN DETOXIFICATION OF RABBITS

\section{Method}

The bladder was first emptied by catheterization. Santonin was then injected intravenously by the auricular vein and the urine collected after 3 hours. Santonin was again injected immediately in the same dose and the three-hour urine collected. The amounts of $\beta$-hydroxysantonin excreted in 
the first and second urine are designated as $a_{0}$ and $b_{0}$ and the value, $\left(b_{0} / a_{0}\right) \times$ 100 , is calculated. On the following day, the same procedure was repeated except that thiamine was injected together with santonin at the second injection. The amounts of $\beta$-hydroxysantonin excreted in the first and second urine are designated as $a_{\mathrm{x}}$ and $b_{\mathrm{x}}$ and the value, $\left(b_{\mathrm{x}} / a_{\mathrm{x}}\right) \times 100$, is calculated. If $\left(b_{\mathrm{x}} / a_{\mathrm{x}}\right) \times 100>\left(b_{0} / a_{0}\right) \times 100$, the vitamin added to santonin can be considered to have accelerated the oxidation of santonin, i.e. santonin detoxification. Since the oxidation of santonin takes place mostly in the liver, the substance can be assumed to accelerate liver function. With this method, it is possible to eliminate daily fluctuations in liver function, and a small number of rabbits are sufficient for the test. In the present experiment, three rabbits weighing 1900-2100 g were used: (a) After examining the CoC effect, thiamine effect was tested. (b) After examining the thiamine effect, the effect of thiamine propyl disulflde (TPD) was tested. (c) After examining the TPD effect, the effect of $\mathrm{CoC}$ was tested. The dosage of santonin was $8 \mathrm{mg}$ per $\mathrm{kg}$. The dosages of thiamine, $\mathrm{CoC}$, and TPD were 5,7 and $5 \mathrm{mg}$ respectively.

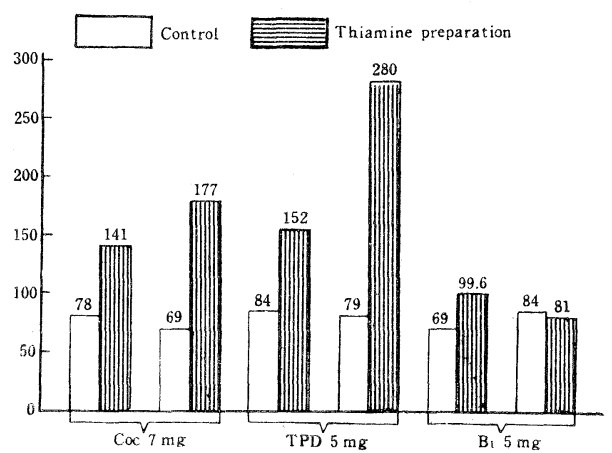

Fia. 1 Comparative Effect of Thiamine, Cocarboxylase and Thiamine Propyl Disulfide on Santonin Detoxification of Rabbits

The $\beta$-hydroxysantonin in the urine was determined according to the following procedure: The sample was colored with 10 per cent $\mathrm{NaOH}$ and determined photometrically at $510 \mathrm{~m} \mu$ within 10 seconds, Azorubin $\mathrm{S}$ solution $\left(1: 10^{5}\right)$ being used as a standard solution.

\section{Results}

As shown in Fig. 1, the injection of $5 \mathrm{mg}$ thiamine gave a result differing little from the control animals in both cases. However, an increase of 2-4 times was observed after injection of $7 \mathrm{mg} \mathrm{CoC}$ or $5 \mathrm{mg}$ TPD, suggesting that both $\mathrm{CoC}$ and TPD

accelerate a liver function.

\section{ESTERIFIED THIAMINE LEVEL OF BLOOD FOLLOWING INSULIN ADMINISTRATION}

\section{Method}

The test subject was a genuine diabetes mellitus patient. On the first day, the subject was ordered to completely empty his bladder early in the morning before breakfast and $12 \mathrm{ml}$ of blood was withdrawn immediately, after which 10 units of standard insulin was injected subcutaneously. Hereafter, approximately $30 \mathrm{~g}$ of bread and about a half cup of tea were given. After 2 hours, $1 \mathrm{mg}$ thiamine was injected intravenously and 30 minutes later blood $(12 \mathrm{ml})$ was again withdrawn. After another 30 minutes, viz., 3 hours after urination, urine was collected. Blood sugar was measured prior to, and every one hour after, the injection of insulin. Thiamine was determined in 
the two blood samples.

On the second day, the same procedure was carried out except for an injection of insulin and measurement of blood sugar.

\section{Results}

As can be seen in Fig. 2, the blood sugar level was $160 \mathrm{mg} / 100 \mathrm{ml}$ at first but gradually decreased following an injection of insulin, especially marked at 2 and 3 hours. It is assumed, therefore, that the insulin activity is fairly high during

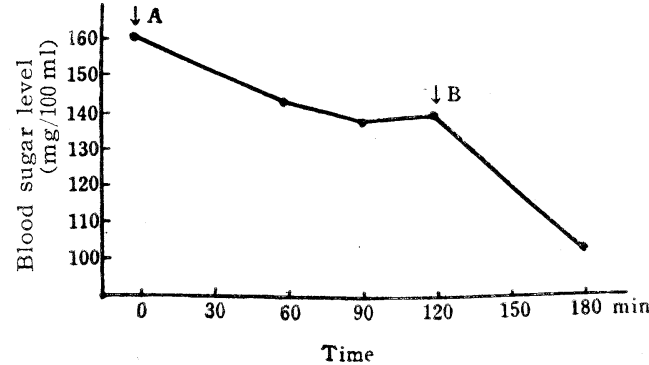

FiG. 2 Effect of Insulin on the Esterification of Thiamine in a Diabetes Mellitus Patient

A, Insulin $10 \mathrm{u}$. subcutaneously injected.

$\mathrm{B}$, Thiamine, $1 \mathrm{mg}$, intravenously injected. this period. Thiamine was injected at 2 hours; therefore, if insulin accelerates phosphorylation ofthiamine, it should have an adequate effect.

Determination of the thiamine level of the blood and urine revealed, as shown in Table IV, that the total and esterified thiamine levels of the blood

TABLE IV

Effect of Insulin Injection on the Blood Esterified Thiamine Level and Urinary Thiamine Excretion

\begin{tabular}{l|c|c|c|c|c}
\hline & \multicolumn{3}{|c|}{ Blood thiamine level $(\gamma / 100 \mathrm{ml})$} & $\begin{array}{c}\text { Urinary thiamine } \\
\text { excretion } \\
(\gamma)\end{array}$ \\
\cline { 2 - 6 } & Empty stomach & $1 \mathrm{mg}$ thiamine injected & Free \\
\hline $\begin{array}{l}\text { Ester } \\
\text { Insulin not }\end{array}$ & 5.7 & 0.4 & 6.1 & 0.8 & 408.2 \\
\hline $\begin{array}{l}\text { Insulin } \\
\text { administered }\end{array}$ & 5.8 & 0.2 & 6.9 & 0.3 & 358.7 \\
\hline
\end{tabular}

which were originally 6.0 and 5.8 r/100 ml, respectively, became 7.2 and 6.9 $r / 100 \mathrm{ml}$ after injection of insulin and thiamine, i.e., after 2.5 hours. The levels of the total and esterified thiamine on the second day were originally 6.1 and $5.7 \mathrm{r} / 100 \mathrm{ml}$, respectively, which rose to 6.9 and $6.1 \mathrm{r} / 100 \mathrm{ml}$ after injection of thiamine. A comparison of the esterified thiamine level after insulin injection with that without injection revealed that it was higher by $0.8 \mathrm{r} / 100 \mathrm{ml}$ after injection. This difference is too small to give a definite conclusion, but the urinary thiamine excreted for 3 hours was found to be less by $49.5 \gamma$ after insulin injection. A rise in the esterified thiamine in the blood may pressumably accompany with the fall in the urinary thiamine in agreement with the results obtained by the authors. It is therefore presumed that insulin promotes thiamine phosporylation.

\section{DISCUSSION}

The active form of thiamine is thiamine pyrophosphate and thiamine 
exists largely in this form in blood and other tissues, though very little in amount. The process of phosphorylation in the body, on the other hand, takes place very actively so that a large amount of the vitamin is continuously phosphorylated in the body and this will not be impeded unless the body undergoes a high degree of disturbance. Beriberi is said to be due to a thiamine deficiency plus $\mathrm{x}$ which is a factor still to be clarified. It might be thiaminokinase of Ochoa et al. We have attempted, from the standpoint of urine test, to clarify this unknown factor by searching for a cause which would convert the positive urine test to the negative. The previous experi ment on the fate of the urine test after administering $\mathrm{CoC}$ has been undertaken for this purpose. The result showed that $\mathrm{CoC}$ was superior to thiamine in this effect. This was especially the case with the phenol- $\mathrm{FeCl}_{3}$ test which was carried out concomitantly with the urine test. The urine test becomes positive not only in thiamine deficiency but also in liver disturbances in general. It was, therefore, assumed that when liver function is improved by administration of $\mathrm{CoC}$, the urine test should become negative parallel with the phenol- $\mathrm{FeCl}_{3}$ test, but this was not always the case. It was, therefore, assumed that $\mathrm{CoC}$ had an accelerating action of some special function. Markees et al. (6) reported that massive doses of $\mathrm{CoC}$ were effective in diabetic and hepatic coma.

If $\mathrm{CoC}$ has a special action, how then does it differ from thiamine? As Markees administered $\mathrm{CoC}$ by injection, it can be assumed that only a small quantity is excreted, the remainder entering the tissues as needed. Inouye and Katsura (7), however, have reported that $\mathrm{CoC}$ introduced in the body is rapidly hydrolyzed and excreted in the urine at about the same rate as thiamine. $\mathrm{CoC}$ and thiamine were, therefore, administered in equimolar amounts and the rise in the thiamine level of the blood and urinary excretion were examined. In one normal subject, $\mathrm{CoC}$ appeared to have a slightly superior effect on blood thiamine, but in the other subjects there was little significant difference. In vitro experiments on the transfer of both thiamine and $\mathrm{CoC}$ into erythrocytes were conducted, but, as reported by others, scarcely any transfer into erythrocytes was recognized and no difference was observed between the two. However, a marked difference was found in the activity. This being suggested to be greatest in liver function, santonin detoxification test was conducted. It was found that thiamine had little effect on the detoxifying action, whereas $\mathrm{CoC}$ had a pronounced beneficial effect on the action. Thiamine propyl disulfide was also found to have a similar beneficial effect. Judging from these results, it is presumed that $\mathrm{CoC}$ is closely related to liver function.

The next question is how and when thiaminokinase in the liver is inactivated or activated. Martin (8) reported that the action of insulin is not pronounced if a sufficient amount of thiamine is not supplied. Foà, Smith and Weinstein (9) suggested that insulin catalyzed the esterification of thiamine and that insulin was required for thiamine activity. Studies were, therefore, carried out by the authors on a diabetic patient to whom, following an injection of insulin, thiamine was administered at the time when the effect of insulin was assumed to be the highest and the degree of esterification was 
examined. As a result, a slight rise in the esterified thiamine level in the blood and a fall in urinary thiamine excretion following insulin injection were observed as compared with the non-loaded control. These findings, however, remain to be settled, owing to the too small numbers of the test subjects. Machida (10) has reported similar findings, though different in the method. The relation of the insulin action to thiaminokinase is still not clear, but regardless of whether it is directly or indirectly involved, it is believed that other factors which accelerate the thiamine esterification exist besides those under discussion.

\section{SUMMARY}

Comparative clinical studies on the effect of thiamine and cocarboxylase wereconducted using the Sawada urine test, liver function test (Miyaji's phenol$\mathrm{FeCl}_{3}$ test), rise in blood thiamine level, urinary thiamine excretion, transfer of thiamine into erythrocytes, santonin detoxification test and esterification of thiamine following administration of insulin as criteria. The following results were obtained:

1. There was litttle difference in effect between thiamine and cocarboxylase using the three-hour method of the urine test. With the one-hour method, however, cocarboxylase was found to have a superior effect, the difference being fairly significant. With the phenol- $\mathrm{FeCl}_{3}$ test, cocarboxylase was found to be superior without exception.

2. Under the conditions of this experiment, no difference between thiamine and cocarboxylase was detected in regards to their effect on blood thiamine level and urinary thiamine excretion.

3. There was scarcely any transfer of thiamine or cocarboxylase into erythrocytes in an in vitro experiment.

4. Thiamine had little effect on the detoxification of santonin in rabbits, whereas cocarboxylase as well as thiamine propyl disulfide manifested an intensive beneficial effect.

5. When thiamine is injected in a diabetic patient following insulin injection, there is a rise in the esterified thiamine level in the blood and a decrease in urinary thiamine excretion as compared with the non-loaded experiment.

\section{REFERENCES}

1. Ochoa, S., Nature 142, 356 (1938) ; Biochem. J. 33, 1262 (1939).

2. Leuthardt, F., and Nielsen, H., Helv. Chim. Acta 35, 1196 (1952).

3. Sewaki, M., Fukuoka Acta Medica (Japanese) 42, 737 (1951).

4. Sawada, T., J. Japan Med. Assoc. (Japanese) 36, 157 (1948) ; 37, 136 (1948) ; 38, 164 (1949).

5. Miyaji, K., Medicine and Biology (Japanese) 15, 270 (1949).

6. Markees, S., Schweiz. med. Wschr. 79, 931 (1949).

7. Inoyue, K., and Katsura, E., Vitamins 7, 990 (1954) ; 7, 1099 (1954).

8. Matrin, R. W., Z. physiol. Chem. 248, 242 (1937).

9. Foà, P. P., Smith, J. A., and Weinstein, H. R., Arch. Biochem. 13, 449 (1947).

10. Machida, K., J. Vitaminol. 2, 216 (1956). 